Archives de sciences sociales des religions

$164 \mid 2013$

Bulletin Bibliographique

\title{
Suzanne Tunc, Ludmila Javorova. Histoire de la première femme prêtre
}

Paris, Temps présent, 2012, 151 p.

\section{Sabine Rousseau}

\section{(2) OpenEdition}

\section{Journals}

Édition électronique

URL : http://journals.openedition.org/assr/25650

DOI : $10.4000 /$ assr. 25650

ISSN : $1777-5825$

Éditeur

Éditions de l'EHESS

Édition imprimée

Date de publication : 30 décembre 2013

Pagination : 299

ISSN : 0335-5985

Référence électronique

Sabine Rousseau, "Suzanne Tunc, Ludmila Javorova. Histoire de la première femme prêtre », Archives de sciences sociales des religions [En ligne], 164 | 2013, mis en ligne le 14 mars 2014, consulté le 21 septembre 2020. URL : http://journals.openedition.org/assr/25650 ; DOI : https://doi.org/10.4000/ assr.25650

Ce document a été généré automatiquement le 21 septembre 2020.

(C) Archives de sciences sociales des religions 


\section{Suzanne Tunc, Ludmila Javorova.} Histoire de la première femme prêtre

Paris, Temps présent, 2012, 151 p.

Sabine Rousseau

\section{RÉFÉRENCE}

Suzanne Tunc, Ludmila Javorova. Histoire de la première femme prêtre, Paris, Temps présent, 2012, $151 \mathrm{p}$. 
1 Le dernier chapitre éclaire le point de vue et le propos du livre: il s'agit d'un ouvrage militant qui plaide pour l'ordination des femmes dans l'Église catholique romaine. Suzanne Tunc, théologienne membre de Femmes et Hommes en Église, retrace le récit d'une femme ordonnée prêtre en 1970 par un évêque de l'Église clandestine tchèque sous régime communiste. Elle utilise pour narrer cette histoire hors du commun un ouvrage américain de Miriam Therese Winter, Out of the Depths. The Story of Ludmila Javorova Ordained Roman Catholic Priest, paru en 2001.

2 Ludmila Javorova a 38 ans quand l'évêque tchèque clandestin Felix Maria Davidek l'ordonne secrètement selon le rituel d'ordination romain. Très impliquée dans la communauté clandestine fondée par


Davidek (après quatorze ans de prison entre 1950 et 1964), la Koinotes, elle fait office de "vicaire apostolique » de l'évêque depuis le milieu des années 1960, partageant les responsabilités avec lui. Convaincu de la nécessité de permettre aux femmes d'accéder au ministère ordonné afin de satisfaire "les besoins de l'Église ", notamment des femmes et particulièrement des religieuses en quête de secours spirituel, Davidek n'hésite pas à la faire prêtre malgré l'hostilité de la plupart des membres de l'Église clandestine de Tchécoslovaquie. Pour Davidek, il n'existe aucun fondement théologique ou scripturaire à l'exclusion des femmes du sacerdoce.

3 Cette ordination de 1970 reste secrète (même dans le cercle familial qui l'ignore) jusqu'en 1995 où elle est dévoilée par la presse, six ans après la Révolution de Velours et la chute du communisme. Elle est alors considérée comme invalide par le Vatican qui interdit à Ludmila Javorova, convoquée à Rome, d'exercer son ministère.

4 Au-delà du ton hagiographique qu'il prend souvent en exaltant le caractère prophétique de l'action de Félix Davidek et le courage de Ludmila Javorova, ce récit intéresse l'historien(ne) particulièrement pour le contexte politique et religieux dans lequel il se situe. Il dépeint le fonctionnement d'une communauté clandestine dans le régime communiste, avec son séminaire où sont enseignées en cachette la théologie et l'exégèse marquées par l'esprit du Concile Vatican II, son réseau de candidats au presbytérat qu'il faut faire ordonner en RDA (Mgr Schaffran en ordonne cinq entre 1967 et 1971), son "système $\mathrm{D}$ » (dit des «facilités mexicaines ») pour ordonner des évêques «suppléants» sans autorisation du Vatican ni de l'État. Dans cette communauté du "désert », il est intéressant de voir à l'œuvre à la fois des audaces comme l'ordination d'hommes mariés et de femmes sous l'impulsion d'une personnalité comme Davidek très soucieux de participer à l'aggiornamento, et des crispations conservatrices contre toute "aventure théologique». La question de l'ordination des femmes cristallise ces dissensions au sein de l'Église clandestine: 
quand Davidek convoque un concile clandestin sur ce thème en 1970, des évêques parmi ceux qu'il avait ordonnés font sécession et créent un groupe dissident qui quitte la Koinotes.

5 Après la chute du communisme en 1989, le Vatican trouve des solutions pour réintégrer dans l'Église les prêtres mariés (dans un diocèse de l'Église catholique grecque) ou les évêques clandestins en procédant à des réordinations, mais déclare invalide toute ordination de femmes. La question de la prêtrise pour les femmes constitue un horizon indépassable, une limite infranchissable pour la grande majorité des hommes d'Église au début des années 1970 .

6 Ainsi, malgré le rideau de fer, la chronologie de la réception de Vatican II à l'Est semble suivre quelque peu celle de sa réception à l'Ouest. Les expériences novatrices comme celle vécue par Félix Davidek et Ludmila Javorova, une expérience de la collaboration étroite entre un homme et une femme à la direction matérielle et spirituelle d'une communauté religieuse, semblent se concentrer autour de 1968 et avoir suscité un mouvement de réaction qui l'emporte à la fin des années 1970 . 